\title{
Relationships between soil albedos and soil and air temperatures
}

\author{
C. J. Stigter ${ }^{1}$, Y. B. Mjungu ${ }^{1}$, P. B. M. Lutege ${ }^{1}$, J. M. Waryoba ${ }^{1}$, C. O. Othieno ${ }^{2}$ \\ and A. R. Mwampaja ${ }^{1}$ \\ 1 Physics Department, Section Agricultural Physics, University of Dar es Salaam, \\ Dar es Salaam, Tanzania \\ ${ }^{2}$ Tea Research Foundation of Kenya, Kericho, Kenya
}

Received 19 September 1983; accepted 29 December 1983

Key-words: soil albedo, soil temperature, air temperature, microclimate management, mulching

\section{Summary}

Relationships are derived between near-interface soil and air temperatures and the albedos and temperatures of the interface under low evaporation conditions. Simple theoretical approximations of these relationships are established for nearly identical soil conditions with different albedos. A demonstration experiment is discussed which proves that this theory is valid at the surface of plastic-covered dry soil. Field temperatures for bare and black plastic-covered relatively dry soil in Kenya at $7.5 \mathrm{~cm}$ depth are also in good agreement with the theory.

\section{Introduction}

Earth surface temperature and albedo are parameters that have separately gained interest since remote sensing techniques have been widely used. This is true for measurements with sensors kept close to the earth surface (e.g. Waryoba, 1979; Jackson et al., 1980; Stigter et al., 1982a; 1982b) as well as for air-borne sensors (e.g. examples in Fraysse, 1980). It is possible to derive from basic equations of heat transfer in soil and air (e.g. van Wijk, 1966a) relationships between these two surface parameters and near-interface temperatures in soil and air. We derive below such relationships for low evaporation conditions.

These relationships can be of value in ground truth for some remote sensing observations on natural and experimental plots. They may also be useful in evaluations of the effectiveness of especially dry-farming but also other agriculture-related modifications, at or near the earth surface, to reduce or increase soil and air temperatures or to increase water use efficiency. Examples are: manipulations of surface reflectivity and absorption as in changing albedos (e.g. Russell, 1973) and in shading (e.g. Stigter, 1982a); manipulations of soil thermal properties near the' 
surface as in mulching (e.g. Davies, 1975; Gupta et al., 1981; Othieno, 1982; Stigter, 1982b), in conservation tillage (e.g. Unger \& McCalla, 1981) and in drying by drainage (e.g. Tanner, 1974); and manipulations of air properties near the surface as in changing heat and mass transfer coefficients by windbreaks (e.g. Barfield \& Gerber, 1979) or vegetation (e.g. Stigter \& Uiso, 1981). Models needed to describe the effectiveness of solar heating of soil under polyethylene for control of soil-borne pests (Katan, 1980; 1981) and influence of chemical properties (Chen \& Katan, 1980) may also make use of our approach.

The theory described below was developed by the senior author and tested in outdoor demonstration experiments on measuring air temperatures close to the ground (Lutege, 1977; Mjungu, 1979). In this paper we show that the theory is valid at the surface of dry soil under these demonstration conditions. Independent field research in Kenya on soil temperatures under tea (Othieno \& Ahn, 1980; Othieno, 1982) recently offered data which also support the theory, as will be shown below.

\section{Theory}

The partial differential equation of heat conduction in one dimension has for harmonic temperature variations in homogeneous soil the general solution (e.g. van Wijk \& de Vries, 1966):

$$
\theta(z, t)=\bar{\theta}_{\mathrm{s} z}+{ }^{A} \theta_{0} \exp (-z / D) \sin \left(\omega t+\Phi_{0}-z / D\right)
$$

where $\theta(z, t)$ is the temperature at depth $z$ and time $t$

$\bar{\theta}_{\mathrm{s} z}$ is the average temperature at depth $z$

${ }^{A} \theta_{0}$ is the temperature amplitude at the surface

$D=\left(2 \lambda_{s} / C_{s} \omega\right)^{1 / 2}$ is the damping depth for a soil of thermal conductivity $\lambda_{\mathrm{s}}$ and volumetric heat capacity $C_{\mathrm{s}}$

$\Phi_{0}=\omega t_{0}$ is a phase constant

$\omega$ is the angular frequency of the harmonic variations.

The simultaneous solution of the same equation in air with constant volumetric heat capacity $C_{\mathrm{a}}$ and an (apparent) thermal conductivity of $\lambda_{\mathrm{a}}=b\left(z^{\prime}+z_{0}\right)$, increasing linearly with height as in purely mechanical convection cases, is for $r \ll 1$ (van Wijk \& de Vries, 1966):

$$
\begin{aligned}
\theta\left(z^{\prime}, t\right) & =\bar{\theta}_{\mathrm{a} z^{\prime}}+{ }^{A} \theta_{0}\left[\ln (\gamma r / 2) / \ln \left(\gamma r_{0} / 2\right)\right] \sin \left(\omega t+\Phi_{0^{-}}\right. \\
& \left.-\operatorname{arct}(4 \ln (\gamma r / 2) / \pi)+\operatorname{arct}\left(4 \ln \left(\gamma r_{0} / 2\right) / \pi\right)\right)
\end{aligned}
$$

where $\bar{\theta}_{\mathrm{az}}$ is the average temperature at height $z^{\prime}$ above the soil

$r=2\left(\lambda_{\mathrm{a}} C_{\mathrm{a}} \omega\right)^{1 / 2 / b}$ is a constant as long as $b$ is constant

$r_{0}=2\left(z_{0} C_{\mathrm{a}} \omega / b\right)^{1 / 2}$ is a constant as long as $b$ is constant

$\gamma=1.78$ is Euler's constant.

It follows from Eq. 1 and 2 that at any depth $z$ or any height $z^{\prime}$ we have for two soils $(1,2)$ of equal damping depth (or thermal diffusivity $\lambda_{\mathrm{s}} / C_{\mathrm{s}}$ ) and roughness under equal atmospheric exposure: 


$$
\frac{\theta_{1}(z, t)-\bar{\theta}_{\mathrm{s} 1 z}}{\theta_{2}(z, t)-\bar{\theta}_{\mathrm{s} 2 z}}=\frac{\theta_{1}\left(z^{\prime}, \mathrm{t}\right)-\bar{\theta}_{\mathrm{a} 1 z^{\prime}}}{\theta_{2}\left(z^{\prime}, t\right)-\bar{\theta}_{\mathrm{a} 2 z^{\prime}}}=\frac{{ }^{A} \theta_{01}}{{ }^{A} \theta_{02}}
$$

$\bar{\theta}_{\mathrm{sl} z}, \bar{\theta}_{\mathrm{s} 2 z^{\prime}}, \bar{\theta}_{\mathrm{a} 1 z^{\prime}}$ and $\bar{\theta}_{\mathrm{a} 2 z^{\prime}}$ may be functions of $z$ and $t$ which satisfy the heat conduction equation, but are constant over the period covered by $t$. Examples are linear functions of depth or height which are independent of time.

The energy balance equation at the surface is:

$$
(1-\varrho) H_{\mathrm{sh}}-H_{\mathrm{nl}}=H_{\mathrm{a}}+H_{\mathrm{e}}+H_{\mathrm{s}}
$$

where $H_{\mathrm{sh}}$ is the solar radiant flux density

$H_{\mathrm{nl}}$ is the net long-wave radiant flux density

$H_{\mathrm{a}}$ is the sensible heat flux density

$H_{\mathrm{e}}$ is the latent heat flux density, representing evaporation

$H_{\mathrm{s}}$ is the heat flux density to within or out of the soil

$\varrho$ is the surface albedo.

If the zero point of the time scale is chosen such that $\Phi_{0}$ in Eq. 1 and Eq. 2 is zero, and if it is assumed that net long-wave radiation varies in phase with the surface temperature (cf. Eq. 14 below) and that $H_{\mathrm{a}}$ and $H_{\mathrm{e}}$ have the same phase difference, which holds as long as a similarity assumption applies to sensible heat and water vapour transfer, then (van Wijk \& de Vries, 1966):

$$
\begin{aligned}
& H_{\mathrm{nl}}=\bar{H}_{\mathrm{nl}}+{ }^{A} H_{\mathrm{nl}} \sin \omega t \\
& H_{\mathrm{sh}}=\bar{H}_{\mathrm{sh}}+{ }^{A} H_{\mathrm{sh}} \sin \left(\omega t+\Phi_{\mathrm{sh}}\right) \\
& H_{\mathrm{a}}=\bar{H}_{\mathrm{a}}+{ }^{A} H_{\mathrm{a}} \sin \left(\omega t+\Phi_{\mathrm{a}}\right) \\
& H_{\mathrm{e}}=\bar{H}_{\mathrm{e}}+{ }^{A} H_{\mathrm{e}} \sin \left(\omega t+\Phi_{\mathrm{a}}\right) \\
& H_{\mathrm{s}}=\bar{H}_{\mathrm{s}}+{ }^{A} H_{\mathrm{s}} \sin (\omega t+\pi / 4)
\end{aligned}
$$

With the common approximation $\bar{H}_{\mathrm{s}}=0$ we get from Eq. 4 with Eq. 5 :

$$
(1-\varrho) \bar{H}_{\mathrm{sh}}-\bar{H}_{\mathrm{nl}}=\bar{H}_{\mathrm{a}}+\bar{H}_{\mathrm{e}}
$$

but also:

$$
\begin{aligned}
& (1-\varrho){ }^{A} H_{\mathrm{sh}} \sin \left(\omega t+\Phi_{\mathrm{sh}}\right)-{ }^{A} H_{\mathrm{n} l} \sin \omega t= \\
& =\left({ }^{A} H_{\mathrm{a}}+{ }^{A} H_{\mathrm{e}}\right) \sin \left(\omega t+\Phi_{\mathrm{a}}\right)+{ }^{A} H_{\mathrm{s}} \sin (\omega t+\pi / 4)
\end{aligned}
$$

By developing $\sin (\omega t+\Phi)$ one derives from Eq. 7:

$$
(1-\varrho){ }^{A} H_{\mathrm{sh}} \cos \Phi_{\mathrm{sh}}-{ }^{A} H_{\mathrm{nl}}=\left({ }^{A} H_{\mathrm{a}}+{ }^{A} H_{\mathrm{e}}\right) \cos \Phi_{\mathrm{a}}+{ }^{A} H_{\mathrm{s}} / 2^{1 / 2}
$$




\section{J. STIGTER ET AL.}

and

$$
(1-\varrho){ }^{A} H_{\mathrm{sh}} \sin \Phi_{\mathrm{sh}}=\left({ }^{A} H_{\mathrm{a}}+{ }^{A} H_{\mathrm{c}}\right) \sin \Phi_{\mathrm{a}}+{ }^{A} H_{\mathrm{s}} / 2^{1 / 2}
$$

Van Wijk \& de Vries (1966) derived from Eq. 8 with Eq. 9:

$$
\operatorname{tg} \Phi_{\mathrm{sh}}=\frac{\left({ }^{A} H_{\mathrm{a}}+{ }^{A} H_{\mathrm{e}}\right) \sin \Phi_{\mathrm{a}}+{ }^{A} H_{\mathrm{s}} / 2^{1 / 2}}{{ }^{A} H_{\mathrm{n} 1}+\left({ }^{A} H_{\mathrm{a}}+{ }^{A} H_{\mathrm{c}}\right) \cos \Phi_{\mathrm{a}}+{ }^{A} H_{\mathrm{s}} / 2^{1 / 2}}
$$

The influence of relative magnitudes of the amplitudes of the net long-wave radiation flux and the soil heat flux on the phase difference between $\Phi_{\mathrm{sh}}$ and $\Phi_{\mathrm{a}}$ can thus be determined. Van Wijk \& de Vries give examples for $H_{\mathrm{e}}=0 . \bar{H}_{\mathrm{a}}$ is taken by them to be approximately zero. This is correct as long as average net radiation equals average evaporation. For dry soil conditions this needs higher wind speeds and/or lower net radiation than for wet ones.

We derive from Eq. 7 for the two soils of Eq. 3, in the approximation of identical $\Phi_{\mathrm{a}}$ for both soils:

$$
\frac{1-\varrho_{1}}{1-\varrho_{2}}=\frac{{ }^{A} H_{\mathrm{n} 11} \sin \omega t+\left({ }^{A} H_{\mathrm{a} 1}+{ }^{A} H_{\mathrm{e} 1}\right) \sin \left(\omega \dot{t}+\Phi_{\mathrm{a}}\right)+{ }^{A} H_{\mathrm{s} 1} \sin (\omega t+\pi / 4)}{{ }^{A} H_{\mathrm{n} 12} \sin \omega t+\left({ }^{A} H_{\mathrm{a} 2}+{ }^{A} H_{\mathrm{e} 2}\right) \sin \left(\omega t+\Phi_{\mathrm{a}}\right)+{ }^{A} H_{\mathrm{s} 2} \sin (\omega t+\pi / 4)}
$$

We have with Eq. 2 and $H_{\mathrm{a}}=-\lambda_{\mathrm{a}} \delta \theta\left(z^{\prime}, t\right) / \delta z^{\prime}$ at the surface

$$
\begin{aligned}
H_{\mathrm{a}} & =-\lambda_{\mathrm{a}} \partial \bar{\theta}_{\mathrm{az}} / \partial z^{\prime}-{ }^{A} \theta_{0}\left[b / 2 \ln \left(\gamma r_{0} / 2\right)\right] \sin (\omega t+\pi / 2+ \\
& \left.+\operatorname{arct}\left(4 \ln \left(\gamma r_{0} / 2\right) / \pi\right)\right)
\end{aligned}
$$

from which (see Eq. 5c) ${ }^{A} H_{\mathrm{a}}$ and $\Phi_{\mathrm{a}}$ can be read. The first term at the right-hand side is a correction on $H_{\mathrm{a}}$ which is normally small. Indeed for our two soils under identical atmospheric exposure $\Phi_{\mathrm{a}}$ is the same.

We have also with Eq. 1 and $H_{\mathrm{s}}=-\lambda_{\mathrm{s}} \delta \theta(z, t) / \delta z$ at the surface:

$$
H_{s}=-\lambda_{\mathrm{s}} \partial \bar{\theta}_{s z} / \partial z+{ }^{A} \theta_{0}\left(\gamma_{\mathrm{s}} C_{\mathrm{s}} \omega\right)^{1 / 2} \sin (\omega t+\pi / 4)
$$

from which (see Eq. 5e) ${ }^{A} H_{\mathrm{s}}$ follows. The first term at the right-hand side is a correction on $H_{\mathrm{s}}$, which is normally small.

We have finally the well known approximation

$$
{ }^{A} H_{\mathrm{nl}}={ }^{A} \theta_{0}\left(4 \varepsilon \sigma \bar{\theta}_{\mathrm{s} 0}^{3}\right)
$$

with $\bar{\theta}_{\mathrm{s} 0}$ is $\bar{\theta}_{\mathrm{s} z}$ for $z=0$.

With Eq. 12, 13 and 14, Eq. 11 can be written for cases of ${ }^{A} H_{\mathrm{e}} \ll{ }^{A} H_{\mathrm{a}}$ in the simpler form: 


$$
\begin{aligned}
& R=\frac{1-Q_{1}}{1-\varrho_{2}}= \\
& \frac{{ }^{A} \theta_{01}}{{ }^{A} \theta_{02}} \times \frac{4 \varepsilon \sigma \bar{\theta}_{\mathrm{s} 10}^{3} \sin \omega t-b / 2 \ln \left(\gamma r_{0} / 2\right) \sin \left(\omega t+\Phi_{\mathrm{a}}\right)+\left(\lambda_{\mathrm{s} 1} C_{\mathrm{s} 1} \omega / 2\right)^{1 / 2} \sin (\omega t+\pi / 4)}{4 \varepsilon \sigma \bar{\theta}_{\mathrm{s} 20}^{3} \sin \omega t-b / 2 \ln \left(\gamma r_{0} / 2\right) \sin \left(\omega t+\Phi_{\mathrm{a}}\right)+\left(\lambda_{\mathrm{s} 2} C_{\mathrm{s} 2} \omega / 2\right)^{1 / 2} \sin (\omega t+\pi / 4)}= \\
& =K \frac{{ }^{A} \theta_{01}}{{ }^{A} \theta_{02}} \simeq \frac{{ }^{A} \theta_{01}}{{ }^{A} \theta_{02}}
\end{aligned}
$$

Of course Eq. 8 and 9 would each yield the same result as Eq. 11, with the same approximations. If we now combine Eq. 3 with Eq. 15 for $K=1$ we finally get:

$$
R=\frac{1-\varrho_{1}}{1-\varrho_{2}}=\frac{\theta_{1}(z, t)-\bar{\theta}_{\mathrm{s} 1 z}}{\theta_{2}(z, t)-\bar{\theta}_{\mathrm{s} 2 z}}=\frac{\theta_{1}\left(z^{\prime}, t\right)-\bar{\theta}_{\mathrm{a} 1 z^{\prime}}}{\theta_{2}\left(z^{\prime}, t\right)-\bar{\theta}_{\mathrm{a} 2 z^{\prime}}}
$$

\section{Discussion of the theory}

As long as the surface is completely wet, ${ }^{A} H_{\mathrm{e}}$ is under most atmospheric conditions related to ${ }^{A} H_{\mathrm{a}}$ through the surface temperature, which determines one of the two vapour pressures by the difference of which water vapour flow is driven. The other, atmospheric vapour pressure, is very often rather conservative (e.g. Dale, 1981) and evaporation is relatively low at night under non-heat-advection conditions. In such cases high values of ${ }^{A} H_{\mathrm{e}}$ will only occur with relatively high values of ${ }^{A} H_{\mathrm{a}} . \mathrm{Be}$ cause of the exponential form of the temperature/saturated vapour pressure relationship, ${ }^{\mathrm{A}} \mathrm{H}_{\mathrm{e}}$ will not have a linear dependence on ${ }^{A} \theta_{0}$ unless the latter is relatively small.

For drier soils ${ }^{A} H_{\mathrm{e}} \simeq \bar{H}_{\mathrm{e}}$ is an even better approximation. Using this in Eq. 5 for all cases in which evaporation becomes zero at night and has a sine wave trend, one gets in the full expression of Eq. 15 a multiplication factor to the second term of numerator and denominator of $1+1 / \beta\left(1+\sin \left(\omega t+\Phi_{\mathrm{a}}\right)\right)$. Here $\beta$ is the instantaneous Bowen ratio $H_{\mathrm{a}} / H_{\mathrm{e}}$. Such a relationship with ${ }^{A} \theta_{0}$ is in line with field observations (e.g. Lonnqvist, 1962). For two soils with approximately the same $\beta$ these terms are again almost equal. For very low evaporation this multiplication term becomes close to 1 of course.

Further implications of $K \approx 1$ (and of identical $\Phi_{\text {sh }}$ (Eq. 10)) are that either the sum of first and third term in Eq. 15 be small in relation to the second one or this sum is the same in numerator and denominator. For drier soils of course $\lambda C$ is much smaller. This also applies to thermal diffusivity $\lambda / C$ although this is not in all cases uniquely related to water content (e.g. Stigter, 1969; Ghuman \& Lal, 1981). However, an equal $\lambda / C$, which was required in Eq. 3 , and an equal $\lambda C$, which was required in Eq. 15 in case the third term is not small, implies $\lambda_{\mathrm{s} 1}=\lambda_{\mathrm{s} 2}$ and $C_{\mathrm{s} 1}=C_{\mathrm{s} 2}$, so all identical terms in Eq. 15 must then be very nearly similar. For a difference of $10 \mathrm{~K}$ in soil surface temperature we have for an equal $\varepsilon$ an $11 \%$ difference between the two first terms in numerator and denominator of $K$. The significance of this difference is again directly related to the relative magnitude of this term. 
It should be noted that if $\omega$ is not the diurnal fluctuation but belongs to an other cycle, such as from regularly passing clouds, the same theory underlying Eq. 16 applies. Only the heat sharing between soil and air is affected which will make ${ }^{A} H_{\mathrm{s}} /$ ${ }^{A} H_{\mathrm{a}}$ larger when $\omega$ is smaller. This can only understood for the condition of a linearly increasing thermal conductivity with height (van Wijk \& de Vries, 1966) and does not hold when an average conductivity of the air layer at the surface is used (e.g. van Wijk \& Gardner, 1960; Tanner, 1974). But our theory holds for both assumptions.

will apply, of course with comparable approximations, to any equal atmospheric non-periodic change, imposed on the two equal soils with different albedo, from any known boundary and initial temperature conditions satisfying the heat conduction equation. Such cases are thoroughly discussed by van Wijk (1966b). We deal with an application of this kind briefly in the next section. This example is treated extensively by Stigter et al. (1984a).

Eq. 16 holds only for temperatures within a layer fully adapted to the surface (albedo) concerned, with enough fetch available. This 'fetch' problem appears to be small within soils as recently shown by Mahrer \& Katan (1981). In air this is a much larger problem because of the much higher damping depth within air (e.g. ILACO, 1981). It should be reminded that for a boundary layer that is mechanically not well mixed, where thermal instability (in daytime) and or thermal stability are predominant, the condition $r \ll 1$ is not fulfilled because of too low or undefined b values.

\section{Applications of the theory}

We applied the theory outlined above (Eq. 16) to two different cases. The first one was part of an outdoor demonstration experiment on different soil surfaces along high no-shadow walls (Lutege, 1977; Mjungu, 1979; Stigter, 1982; Stigter et al., 1983). The second one is part of an analysis of soil temperatures under tea (Othieno \& Ahn, 1980; Othieno, 1982).

\section{Covered dry soil surfaces of different albedo}

In a $3 \mathrm{~m} \times 1.75 \mathrm{~m} \times 0.2 \mathrm{~m}$ box filled with dry sand two compartments of $3 \mathrm{~m} \times 0.75$ $\mathrm{m}$ were made along $1-\mathrm{m}$ high walls, open at both short sides. The box was placed on wheels and could be turned in such a way that no shades were falling on the surfaces. One of the two compartments was covered with two layers of transparent polyethylene with white paint in between these layers. The other was covered with two layers of black polyethylene. Under conditions of moderate to high natural air flow, making angles with the no-shadow walls smaller than $45^{\circ}$ we measured surface temperatures by thermocouples sandwiched between the polyethylene layers. The sensor locations were at the down wind side of the box in the middle between the walls. Nearly equal air flows were shown to exist above these places using Lambrecht $641 \mathrm{~N}$ heated thermistor anemometers at several heights.

Under the conditions described only the surface albedos are different. This means that under our experimental conditions only the first terms in $K$ in Eq. 15 are different and $\Phi_{\mathrm{sh}}$ is almost equal. Calculations show tg $\Phi_{\mathrm{sh}}$ to be less than $1 \%$ dif- 
Table 1. Temperatures $(1,2)$ and temperature differences with an initial temperature of $28.2^{\circ} \mathrm{C}\left({ }^{A} \theta_{01}\right.$, $\left.{ }^{A} \theta_{02}\right)$ used to check Eq. 15 and Eq. 16. Soil 1 with an albedo of $69 \%$, equal soil 2 with an albedo of $6 \%$.

\begin{tabular}{llllll}
\hline Hour & Temp. 1 & Temp. 2 & ${ }^{A} \theta_{01}$ & ${ }^{A} \theta_{02}$ (calc.) & ${ }^{A} \theta_{02}$ (meas.) \\
1 & 32.2 & 43.2 & 4.0 & 12.1 & 15.0 \\
2 & 34.7 & 48.8 & 6.5 & 19.7 & 20.6 \\
3 & 35.1 & 47.3 & 6.9 & 20.9 & 19.1 \\
4 & 35.3 & 48.9 & 7.1 & 21.5 & 20.7 \\
5 & 34.3 & 46.8 & 6.1 & 18.5 & 18.6 \\
\multirow{2}{*}{ Average } & 34.3 & 47.0 & 6.1 & 18.5 & 18.8 \\
\hline
\end{tabular}

ferent for $10{ }^{\circ} \mathrm{C}$ difference in $\theta_{\mathrm{s} 0}$, and they show $K=1$ to hold within the same error limits.

We covered the two soil surfaces with insulating material for several days and removed this after sunrise with solar height over $30^{\circ}$ when the thermocouples read $28.2 \pm 0.2{ }^{\circ} \mathrm{C}$ at both sides. We then measured hourly averages of the two surface temperatures for the next five hours. Table 1 gives the results comparing the measured temperatures at the black surface with those following from Eq. 16 using the temperatures at the white surface and the albedos measured as $6 \pm 1 \%$ and $69 \pm$ $2 \%$ for the black and the white surface respectively (Waryoba, 1979). In these calculations ${ }^{A} \theta_{0}$ is the difference with the initial equal temperature. Apart from the first hour, where a starting up effect influences the measurements (Stigter et al., 1984a) the differences everywhere are less than $2^{\circ} \mathrm{C}$. The calculated average over five hours is only $0.3{ }^{\circ} \mathrm{C}$ different from the measured one. Using the two temperatures and the black-plastic albedo would have given a white-plastic albedo of $70 \pm$ $2 \%$.

The results show Eq. 15 and Eq. 16 to hold at the surface for a non-periodic phenomenon of gradual release of heat (Stigter et al., 1984a). These results also suggest that application of the theory is after a short period independent of any built-up time of periodic phenomena (Mahrer, 1979) as this is a combination of non-periodic and periodic solutions. With temperatures measured with protected thermometers in the air above the plastic the obvious absence of enough fetch in these within-air experiments was easily demonstrated.

\section{Bare and covered relatively dry soil at $7.5 \mathrm{~cm}$ depth}

In the studies of soil temperatures under tea in Kenya, measurements started, at one depth $(z=7.5 \mathrm{~cm})$ only, before tea plants could influence temperatures under different mulches. We selected the earliest measurements, of Febr./Apr. 1974, when the soil was relatively dry, and compared those temperatures under black plastic and bare soil conditions. From data in February 1975, with measurements at three depths under equally dry conditions, but also from other months, it appears that in bare soil the average temperature is virtually constant with depth and for relatively few cases in which it was not constant it was approximately linear with 


\section{J. STIGTER ET AL.}

Table 2. Average diurnal temperatures at $7.5 \mathrm{~cm}$ depth (February, 1974) for relatively dry bare soi] and equal black-plastic (BP) covered soil (measured and calculated) to check Eq. 16. The soils have an albedo difference of about $10 \%$ (Othieno, 1982). The ratio $R$ is also given. Its average was used in the calculated temperatures, together with the measured average temperatures.

\begin{tabular}{|c|c|c|c|c|c|}
\hline \multirow[t]{2}{*}{ Time } & \multicolumn{4}{|c|}{ Temperature } & \multirow[t]{2}{*}{ Ratio $R$} \\
\hline & bare & $\begin{array}{l}\text { black plastic } \\
\text { measured }\end{array}$ & $\begin{array}{l}\text { black plastic } \\
\text { calculated }\end{array}$ & $\mathrm{T}$ (calc.-meas.) & \\
\hline $02 \mathrm{~h} 00$ & 21.7 & 24.4 & 24.6 & 0.2 & 0.77 \\
\hline $04 \mathrm{~h} 00$ & 20.7 & 23.3 & 23.5 & 0.2 & 0.83 \\
\hline $06 \mathrm{~h} 00$ & 19.8 & 22.0 & 22.5 & 0.5 & 0.78 \\
\hline $08 \mathrm{~h} 00$ & 18.0 & 21.2 & 20.5 & -0.7 & 1.04 \\
\hline $10 \mathrm{ho0}$ & 19.0 & 21.7 & 21.7 & 0.0 & 0.92 \\
\hline $12 \mathrm{~h} 00$ & 21.4 & 24.9 & 24.3 & -0.6 & $(1.60)$ \\
\hline $14 \mathrm{~h} 00$ & 24.6 & 27.7 & 27.8 & 0.1 & 0.95 \\
\hline $16 \mathrm{~h} 00$ & 26.7 & 30.2 & 30.1 & -0.1 & 0.89 \\
\hline $18 \mathrm{~h} 00$ & 27.4 & 30.9 & 30.9 & 0.0 & 0.91 \\
\hline $20 \mathrm{~h} 00$ & 26.0 & 29.3 & 29.4 & 0.1 & 0.92 \\
\hline $22 \mathrm{~h} 00$ & 24.3 & 27.3 & 27.5 & 0.2 & 1.01 \\
\hline $24 \mathrm{~h} 00$ & 22.9 & 25.8 & 25.9 & 0.1 & $(2.38)$ \\
\hline Aver. & 22.7 & 25.7 & $(25.7)$ & 0.2 (abs.) & $0.90 \pm 0.08$ \\
\hline
\end{tabular}

depth. For black plastic the cases of constant average temperature with depth were more rare but many had a linear dependence and only to few cases did none of these conditions apply. This indicates that based on these conditions Eq. 15 and 16 may be used. We therefore used the diurnal pattern monthly averaged over Febr./Apr. 1974 and the albedos as given by Othieno $(1982)$ as $11 \%$ for bare soil $\left(\varrho_{1}=0.11\right)$ and $1 \%$ for black plastic $\left(\varrho_{2}=0.01\right)$. Then $\left(1-\varrho_{1}\right) /\left(1-\varrho_{2}\right)=0.90$.

One may argue that a value of $\varrho_{2}=0.01$ is extremely low for black plastic. We measured $\varrho_{2}=0.06$ in the former experiment. If the albedo measurements should be increased, a $\varrho_{1}$ of $0.13 \pm 0.02$ and a $\varrho_{2}$ of $0.05 \pm 0.01$ would give a ratio of $0.92 \pm$ 0.03 , covering the result with the original data. With the two-hourly diurnal temperature pattern as given in Table 2 we obtained values for ratio $R$ in Eq. 16 as given in the same Table. $R=\left(\theta_{1}(7.5, t)-\bar{\theta}_{\mathrm{s} 1(7.5)}\right) /\left(\theta_{2}(7.5, t)-\bar{\theta}_{\mathrm{s} 2(7.5)}\right)$. If we remove the data at $12 \mathrm{~h} 00$ and $24 \mathrm{~h} 00$, the average we obtain is 0.90 with a standard deviation of \pm 0.08 . For March and April we obtained in the same way $0.9 \pm 0.3$ and $0.9 \pm 0.1$ respectively.

For these data at $12 \mathrm{~h} 00$ and $24 \mathrm{~h} 00$, when the average diurnal wave passes the aver... temperature level, the ratio at small temperature differences is least accurate because of small depth and inhomogeneity differences counting heaviest there. Nevertheless, Eq. 16 appears to be accurate in forecasting at these times as well.

The average accuracy of $0.2{ }^{\circ} \mathrm{C}$ with which the temperature wave under black plastic could be calculated from the temperature wave in bare soil, the albedos and average temperatures shows the validity of the derived theory under those conditions (Table 2). These results also demonstrate that the theory applies to not exactly sine wave like phenomena (e.g. Parton \& Logan, 1980). 
It should be realized that for actual temperatures to be known in a soil with a certain albedo from the ones in an identical soil with different albedo, average temperatures as a function of depth should be known or estimated (Stigter et al., 1984b). An evaluation of the applicability of the theory under other conditions (wetter soils, grass mulches, tea shades) has been positive as well (Othieno et al., 1983; Stigter et al., 1984b).

\section{Acknowledgements}

This work is part of the project DTH/UH/MV/Agr. Physics, supported by the Directorate General of International Cooperation, Ministry of Foreign Affairs, Netherlands, with approval from the Treasury, Government of the United Republic of Tanzania. The project is technically assisted by an advisory group of the Department of Physics and Meteorology, Agricultural University, Wageningen, Netherlands. We thank Dr M. C. Gough of the Tropical Products Institute (U.K.) for improving the English of a draft of this paper.

\section{References}

Barfield, B. J. \& J. F. Gerber (Ed.), 1979. Modification of the aerial environment of plants. ASAE Monograph No 2, St. Joseph, Michigan.

Chen, Y. \& J. Katan, 1980. Effect of solar heating of soils by transparent polyethylene mulching on their chemical properties. Soil Science 130: 271-277.

Dale, R. F., 1981. Existing meteorological networks. In: A. Weiss (Ed.), Computer techniques and meteorological data applied to problems of agriculture and forestry: a workshop, pp. 56-72. National Science Foundation, Anaheim.

Davies, J. W., 1975. Mulching effects on plant climate and yield. Technical Note No 136, WMO No. 388 , Geneva.

Fraysse, G. (Ed.), 1980. Remote sensing application in agriculture and hydrology. A. A. Balkema, Rotterdam.

Ghuman, B. S. \& R. Lal, 1981. Predicting diurnal temperature regime of a tropical soil. Soil Science 132: $247-252$

Gupta, S. C., J. K. Radke and W. E. Larson, 1981. Predicting temperatures of bare and residue covered soils with and without a corn crop. Proceedings Soil Science Society of America 45: 405-412.

ILACO (Ed.), with D. A. de Vries \& C. J. Stigter, 1981. Climate. Ch. 1 in: Agricultural compendium for rural development in the tropics and subtropics. Elsevier, Amsterdam.

Jackson, R. D., P. J. Pinter, Jr., R. J. Reginato \& S. B. Idso, 1980. Hand-held radiometry. USDA, SEA, Agricultural Review Manual ARM-W-19.

Katan, J., 1980. Solar pasteurization of soils for disease control: status and prospects. Plant Disease Reporter 64: $450-454$.

Katan, J., 1981. Solar heating (solarization) of soil for control of soil borne pasts. Annual Review of Phytopathology 19: 211-236.

Lonnqvist, O., 1962. On the diurnal variation of surface temperature. Tellus 14: 96-101.

Lutege, P. M. B., 1977. Experiments on different soil surfaces along high no-shadow walls. M.Sc. thesis, University of Dar es Salaam, iii +83 pp.

Mahrer, Y., 1979. Prediction of soil temperatures of a soil mulched with transparent polyethylene. Journal of Applied Meteorology 18: 1263-1267.

Mahrer, Y. \&. J. Katan, 1981. Spatial soil temperature regime under transparent polyethylene mulch: numerical and experimental studies. Soil Science 131: 82-87.

Mjungu, Y. B., 1974. Improved experiments on different soil surfaces along high no-shadow walls (with addendum: a statistical method to check routine meteorological station data). M.Sc. thesis, Universi- 
ty of Dar es Salaam, $\mathrm{x}+105 \mathrm{pp}$.

Othieno, C. O., 1982. Diurnal variations in soil temperature under tea plants. Experimental Agriculture 18: $195-202$.

Othieno, C. O.\& P. M. Ahn, 1980. Effect of mulches on soil temperature and growth of tea plants in Kenya. Experimental Agriculture 16: 287-294.

Othieno, C. O., C. J. Stigter \& A. R. Mwampaja, 1983. On the use of Stigter's ratio in expressing thermal efficiency of grass mulches. (Submitted for publication.) Available as Research Report 1983-2, Section Agricultural Physics, Physics Department, University of Dar es Salaam.

Parton, W. J. \& J. A. Logan, 1981. A model for diurnal variation in soil and air temperature. Agricultural Meteorology 23: 205-216.

Russell, E. W., 1973. Soil conditions and plant growth, 10th ed. Longman, London.

Stigter, C. J., 1969. On measuring properties of soils by thermal methods with special reference to the contact method. Netherlands Journal of Agricultural Science 17: 41-49.

Stigter, C. J., 1982a. Shading: a traditional method of microclimate manipulation. In: C. J. Stigter (Ed.), Newsletter No 8, National Agrometeorological Committee, Directorate of Meteorology, Dar es Salaam (Tanzania).

Stigter, C. J., 1982b. Mulching as a traditional method of microclimate manipulation. In: C. J. Stigter, C. B. Uiso \& N. F. Jiwaji, (Ed.), Newsletter No 9, National Agrometeorological Committee, Directorate of Meteorology, Dar es Salaam (Tanzania).

Stigter, C. J., 1982c. Environmental physics, agricultural research and development. Inaugural Lecture Series No 30. Dar es Salaam University Press, Dar es Salaam (Tanzania).

Stigter, C. J. \& C. B. S. Uiso, 1981. Understanding the Piche evaporimeter as a simple integrating mass transfer meter. Applied Scientific Research 37: 213-223.

Stigter, C. J., N. T. Jiwaji \& M. M. Makonda, 1982a. A calibration plate to determine the performance of infrared thermometers in field use. Agricultural Meteorology 26: 279-283.

Stigter, C. J., M. M. Makonda \& N. T. Jiwaji, 1982b. Improved field use of a simple infrared thermometer. Acta Botanica Neerlandica 31: 379-389.

Stigter, C. J., Y. B. Mjungu \& J. M. Waryoba, 1984a. An outdoor demonstration experiment on the effect of soil albedo on soil surface temperature. American Journal of Physics (in press).

Stigter, C. J., C. O. Othieno \& A. R. Mwampaja, 1984b. An interpretation of temperature patterns under mulched tea at Kericho, Kenya. Agricultural Meteorology (in press).

Tanner, C. B., 1974. Microclimate modification: basic concepts. Horticultural Science 9: 555-560.

Unger, P. W. \& T. M. McCalla, 1981. Conservation tillage systems. Advances in Agronomy 33: 1-58.

Wijk, W. R. van (Ed.), 1966a. Physics of plant environment. North-Holland, Amsterdam.

Wijk, W. R. van, 1966b. General temperature variations in a homogeneous soil. In: W. R. van Wijk (Ed.), Physics of plant environment. Ch. 5. North-Holland, Amsterdam.

Wijk, W. R. van \& M. R. Gardner, 1960. Soil temperature and the distribution of heat between soil and air. Transactions 7th International Congress on Soil Science (Madison, Wisconsin): 195-202.

Wijk, W. R. van \& D. A. de Vries, 1966. Periodic temperature variations. In: W. R. van Wijk (Ed.), Physics of plant environment, Ch. 4. North-Holland, Amsterdam.

Waryoba, J. M., 1974. Field comparison under Tanzanian conditions to obtain total global radiation and albedo values for some relevant surfaces. M.Sc. thesis, University of Dar es Salaam, xvi + $141 \mathrm{pp}$. 